\title{
Adjuvant treatment with polyadenylic-polyuridylic acid in operable breast cancer: updated results of a randomised trial
}

\author{
JEAN LACOUR, FANNY LACOUR, ALFRED SPIRA, MICHAEL MICHELSON, JEAN-YVES PETIT, \\ GENEVIEVVE DELAGE, DANIELLE SARRAZIN, GENEVIEVVE CONTESSO, JEANNINE VIGUIER
}

\begin{abstract}
The results of a randomised trial of polyadenylicpolyuridylic acid given as adjuvant treatment for operable breast cancer were reviewed after a mean follow up period of 87 months. Of the 300 patients included in the original trial, 145 had been allocated to conventional treatment alone and served as controls.

At the time of review the overall survival of the group given polyadenylic-polyuridylic acid was significantly improved $(p<0.05)$ as compared with that of the controls given conventional treatment alone. Significant benefit $(p<0.02)$ was also observed among patients with evidence of disease in lymph nodes, the best results occurring in those with up to three invaded nodes, who showed a significant increase in both overall and relapse free survival. No evidence of toxicity was recorded.

These findings confirm the value of polyadenylicpolyuridylic acid as adjuvant treatment for operable breast cancer. Results in an experimental model and in
\end{abstract}

Institut Gustave-Roussy, Villejuif

JEAN LACOUR, MD, head of department of surgical oncology

FANNY LACOUR, MD, director of research, CNRS, chief of laboratory of immunology

JEAN-YVES PETIT, $M D$, chief of reconstructive surgery

GENEVIEVE DELAGE, BS, research associate, INSERM, laboratory of immunology

DANIELLE SARRAZIN, MD, chief of cobalt therapy

GENEVIĖVE CONTESSO, $M D$, head of department of pathology

JEANNINE VIGUIER, research technician, department of medical statistics

Unite 21 de Recherches Statistiques de l'INSERM, Villejuif ALFRED SPIRA, MD, associate professor

Institut de Biologie Physico-Chimique, Paris

MICHAEL MICHELSON, PHD, director of research, CNRS, chief of service

Correspondence and requests for reprints to: Dr Jean Lacour, Chef du Département de Chirurgie, Institut Gustave-Roussy, 94805 Villejuif-Cedex. patients receiving the adjuvant suggested a possible role of interferon and natural killer (NK) cells in the mechanism of action.

\section{Introduction}

In 1980 we reported the first results of a randomised trial of polyadenylic-polyuridylic acid given as adjuvant treatment for operable breast cancer. ${ }^{1}$ The trial had been conducted at the Institut Gustave-Roussy and had run from November 1972 to December 1979. The entire series comprised 300 patients (155 given adjuvant treatment, 145 given conventional treatment alone), and at the time of the first report the mean follow up period was more than 50 months. As a whole the overall survival was significantly higher in the group given adjuvant treatment, but more particularly relapse free survival in patients with evidence of disease in lymph nodes was also significantly increased in the group given adjuvant treatment.

We now present the results of analysis in January 1983, when the mean duration of follow up was 87 months; we also examine the possible mechanisms of action of polyadenylicpolyuridylic acid.

\section{Patients and methods}

Details of the 300 patients and organisation of the trial have been described. ${ }^{1}$ We included in the trial patients presenting with an infiltrating carcinoma of the breast of medium size (maximum diameter 2-7 cm) whose disease could be staged according to the TNM classification as $T_{2}$ and part of $T_{3}, N_{0}-N_{1}$, and $M_{0}$. Conventional local and regional treatment was the same for all women-surgery alone when the axillary nodes showed no evidence of disease, and surgery plus cobalt therapy when they were invaded.

The patients were randomised into two groups: one $(n=155)$ received conventional treatment plus polyadenylic-polyuridylic acid given intravenously at the rate of one injection of $30 \mathrm{mg}$ a week for six weeks, and the other $(n=145)$ received conventional treatment plus a placebo given according to the same schedule as for the active adjuvant. This second group served as controls. 
Patients were evaluated for the incidence of local and regional recurrences and for distant metastases, and the overall and relapse free survival times were determined.

Follow up-Patients received a complete clinical examination every three months during the first three years, every six months during the next five years, and then once a year. Chest and pelvic radiography was performed routinely once a year, and more often (usually associated with other investigations) when clinical examination disclosed something abnormal.

Statistical analysis was by $\log$ rank tests, ${ }^{2}$ as appropriate.

\section{Results}

Patients given polyadenylic-polyuridylic acid as adjuvant treatment survived significantly longer $(<0 \cdot 05)$ than those given conventional treatment alone (table I, fig 1). The actuarial overall survival rate at eight years was 71 (SE 4)\% in the group given adjuvant treatment and $57(5) \%$ in the controls. No significant difference in relapse free survival was observed between the two treatment groups (table I, fig 2).

A separate analysis was made taking into account nodal state, which is one of the best prognostic factors in breast cancer. Patients who do not have microscopical evidence of disease in lymph nodes (TNM classification $\mathrm{N}_{-}$) have a better prognosis than those who do $\left(\mathrm{N}_{+}\right)$; these patients have a higher risk of metastases and are therefore usually given adjuvant chemotherapy.

In patients without evidence of disease in lymph nodes no significant difference in overall and relapse free survival was observed between the two treatment groups (table II, figs 3 and 4). By contrast, among patients who had shown evidence of disease in lymph nodes $\left(\mathrm{N}_{+}\right)$the overall survival was significantly $(\mathrm{p}<0.02)$ increased in the group given the adjuvant treatment as compared with controls (table II, fig 5). The eight year actuarial overall survival rates in the two groups were respectively, 67 (SE 5) \% and $48(6)^{\circ} \%$. A notable (but non-significant) difference persisted in relapse free survival between the two treatment groups with diseased nodes (table II, fig 6). Analysis in relation to the number of invaded axillary nodes showed that the significant difference in survival occurred essentially in patients with up to three affected nodes (tables II and III).

\section{Discussion}

These results confirm those published in 1980 and indicate that polyadenylic-polyuridylic acid has a beneficial effect on operable breast cancer. Interestingly, in our series this effect was seen almost entirely in the increased survival of patients with spread of the disease to axillary lymph nodes, for whom a general adjuvant treatment is indicated because of the high risk of metastases. This group was also numerically the more important.

In this review we found that the differences in overall survival of patients with diseased lymph nodes were significant $(p<0.02)$, whereas at the first analysis they had been only borderline. ${ }^{1}$ Relapse free survival curves, however, were no longer so significantly different. One possible explanation might be that polyadenylic-polyuridylic acid had delayed the onset of metastases; however, the mean time to relapse was 31 months in the treated group and 26 months in the control group, and this difference was not statistically significant.

The best results were observed in patients with up to three nodes invaded, with both overall and relapse free survival significantly improved. Bonadonna et al reported similar observations in patients given chemotherapy with cyclophosphamide, methotrexate, and fluorouracil (CMF). ${ }^{3}{ }^{4}$ Hence these adjuvant treatments (polyadenylic-polyuridylic acid and $\mathrm{CMF}$ ) seem to be more effective in breast cancer of medium severity -that is, associated with spread to only a limited number of lymph nodes. It is not possible, however, to compare these two adjuvant treatments without a new trial. It would also be impossible to repeat the present trial on a large scale, since no oncologist would agree to withhold adjuvant treatment from a control group of patients with evidence of disease in lymph nodes. In order to confirm indirectly the effect of polyadenylicpolyuridylic acid and compare strictly the respective values of this duplex and chemotherapy with $\mathrm{CMF}$ we have therefore designed a new trial. This controlled, randomised study, undertaken under the auspices of the Federation Nationale des Centres de Lutte Contre le Cancer, applies to breast cancer with associated spread to lymph nodes first treated by mastectomy plus axillary dissection. The patients are randomly allocated to receive either cobalt therapy and polyadenylicpolyuridylic acid or chemotherapy with CMF. Eleven French cancer centres are engaged in the trial and within one year 150 cases have been included.

Two other multicentre trials of polyadenylic-polyuridylic acid have been undertaken for tumours that have failed to respond to adjuvant chemotherapy-namely melanoma and colorectal carcinoma. Both are comparing surgery alone versus surgery plus polyadenylic-polyuridylic acid. The first is being carried out under the direction of the WHO Group on Melanomas, run by $U$ Veronesi, and the second at the Institut GustaveRoussy with the collaboration of four gastrointestinal surgical services in Paris.

TABLE I-Observed $(O)$ and expected $(E)$ numbers of deaths and treatment failures* among patients given conventional treatment and conventional treatment plus adjuvant polyadenylic-polyuridylic acid

\begin{tabular}{|c|c|c|c|c|c|c|c|c|}
\hline \multirow{2}{*}{ Treatment group } & \multicolumn{3}{|c|}{ Deaths } & \multirow{2}{*}{$\begin{array}{l}\text { Significance } \\
(\mathrm{df}=1)\end{array}$} & \multicolumn{3}{|c|}{ Treatment failures } & \multirow{2}{*}{$\begin{array}{l}\text { Significance } \\
(\mathrm{df}=1)\end{array}$} \\
\hline & $\mathrm{O}$ & $\mathrm{E}$ & $\mathrm{O} / \mathrm{E}$ & & $\mathrm{O}$ & $E$ & $\mathrm{O} / \mathrm{E}$ & \\
\hline $\begin{array}{l}\text { Conventional }(n=145) \\
\text { Conventional plus adjuvant }(n=155)\end{array}$ & $\begin{array}{l}51 \\
39\end{array}$ & $\begin{array}{l}41.49 \\
48.51\end{array}$ & $\begin{array}{l}1.23 \\
0.80\end{array}$ & \}$x^{2}=4.04 ; p<0.05$ & $\begin{array}{l}63 \\
61\end{array}$ & $\begin{array}{l}58 \cdot 63 \\
65.35\end{array}$ & $\begin{array}{l}1.08 \\
0.93\end{array}$ & $\chi^{2}=0.62 ; \mathrm{NS}$ \\
\hline
\end{tabular}

*Treatment failure includes death, recurrence of disease, and metastastatic spread.

NS = Not statistically significant.

TABLE II-Observed $(O)$ and expected $(E)$ numbers of deaths and treatment failures in relation to nodal state among patients given conventional treatment and conventional treatment plus adjuvant polyadenylic-polyuridylic acid

\begin{tabular}{|c|c|c|c|c|c|c|c|c|c|c|}
\hline \multirow{2}{*}{$\begin{array}{l}\text { Nodal state } \\
\text { (TNM classification) }\end{array}$} & \multirow{2}{*}{ Treatment group } & \multirow{2}{*}{ No of patients } & \multicolumn{3}{|c|}{ Deaths } & \multirow{2}{*}{$\begin{array}{l}\text { Significance } \\
(\mathrm{df}=1)\end{array}$} & \multicolumn{3}{|c|}{ Treatment failures } & \multirow{2}{*}{$\begin{array}{l}\text { Significance } \\
\quad(\mathrm{df}=1)\end{array}$} \\
\hline & & & $\mathrm{O}$ & $\mathrm{E}$ & $\mathrm{O} / \mathrm{E}$ & & $\mathrm{O}$ & $\mathrm{E}$ & $\mathrm{O} / \mathrm{E}$ & \\
\hline $\begin{array}{l}\mathbf{N} \\
\mathbf{N}\end{array}$ & $\begin{array}{l}\text { Conventional } \\
\text { Conventional plus adjuvant } \\
\text { Conventional } \\
\text { Conventional plus adjuvant }\end{array}$ & $\begin{array}{r}43 \\
52 \\
102 \\
103\end{array}$ & $\begin{array}{r}6 \\
10 \\
45 \\
29\end{array}$ & $\begin{array}{c}7 \cdot 46 \\
8 \cdot 54 \\
35 \cdot 0 \\
39 \cdot 0\end{array}$ & $\begin{array}{l}0 \cdot 80 \\
1 \cdot 17 \\
1 \cdot 29 \\
0 \cdot 74\end{array}$ & $\left\{\begin{array}{l}x^{2}=0.54 ; \mathrm{NS} \\
x^{2}=5.41 ; p \cdot 0.02\end{array}\right.$ & $\begin{array}{l}14 \\
20 \\
49 \\
41\end{array}$ & $\begin{array}{l}15 \cdot 56 \\
18 \cdot 44 \\
42 \cdot 17 \\
47 \cdot 83\end{array}$ & $\begin{array}{l}0.90 \\
1.09 \\
1.16 \\
0.86\end{array}$ & $\begin{array}{l}\chi^{2}=0 \cdot 29 ; \mathrm{NS} \\
\chi^{2}=2 \cdot 08 ; \mathrm{NS}\end{array}$ \\
\hline $\begin{array}{l}\leqslant 3 \mathrm{~N} \cdot \text { nodes } \\
\geqslant 4 \mathrm{~N} \cdot \text { nodes }\end{array}$ & $\begin{array}{l}\text { Conventional } \\
\text { Conventional plus adjuvant } \\
\text { Conventional } \\
\text { Conventional plus adjuvant }\end{array}$ & $\begin{array}{l}59 \\
55 \\
43 \\
48\end{array}$ & $\begin{array}{r}21 \\
8 \\
24 \\
21\end{array}$ & $\begin{array}{l}13 \cdot 4 \\
15 \cdot 6 \\
21 \cdot 14 \\
23 \cdot 86\end{array}$ & $\begin{array}{l}1 \cdot 57 \\
0.51 \\
1 \cdot 14 \\
0 \cdot 88\end{array}$ & $\left\{\begin{array}{l}x^{2}=8.03 ; p \cdot 0.005 \\
x^{2}=0.73 ; N S\end{array}\right.$ & $\begin{array}{l}24 \\
14 \\
25 \\
27\end{array}$ & $\begin{array}{l}17 \cdot 7 \\
20 \cdot 3 \\
23 \cdot 8 \\
28 \cdot 18\end{array}$ & $\begin{array}{l}1.36 \\
0.69 \\
1.05 \\
0.96\end{array}$ & $\begin{array}{l}x^{2}=4 \cdot 18 ; p \cdot 0.05 \\
x^{2}=0 \cdot 11 ; \mathrm{NS}\end{array}$ \\
\hline
\end{tabular}


TABLE III-Eight year actuarial survival in relation to number of axillary nodes affected by disease among patients given conventional treatment and conventional treatment plus adjuvant polyadenylic-polyuridylic acid. Values are percentages ( $S E$ in parentheses)

\begin{tabular}{|c|c|c|c|c|c|c|}
\hline & \multicolumn{2}{|r|}{$<3$ nodes } & \multirow[b]{2}{*}{$\begin{array}{c}\text { Significance } \\
\text { (log rank test) }\end{array}$} & \multicolumn{2}{|r|}{$\geqslant 4$ nodes } & \multirow[b]{2}{*}{$\begin{array}{c}\text { Significance } \\
\text { (log rank test })\end{array}$} \\
\hline & $\begin{array}{l}\text { Conventional } \\
\quad(\mathrm{n}=59)\end{array}$ & $\begin{array}{l}\text { Conventional plus adjuvant } \\
\qquad(\mathrm{n}=55)\end{array}$ & & $\begin{array}{l}\text { Conventional } \\
\quad(n=43)\end{array}$ & $\begin{array}{l}\text { Conventional plus adjuvant } \\
\qquad(\mathrm{n}=\mathbf{4 8})\end{array}$ & \\
\hline $\begin{array}{l}\text { Overall survival } \\
\text { Relapse free survival }\end{array}$ & $\begin{array}{l}55(8) \\
51(8)\end{array}$ & $\begin{array}{l}80(7) \\
68(7)\end{array}$ & $\begin{array}{l}p<0.005 \\
p<0.05\end{array}$ & $\begin{array}{l}42(8) \\
42(8)\end{array}$ & $\begin{array}{l}53(8) \\
42(7)\end{array}$ & $\begin{array}{l}\text { NS } \\
\text { NS }\end{array}$ \\
\hline
\end{tabular}
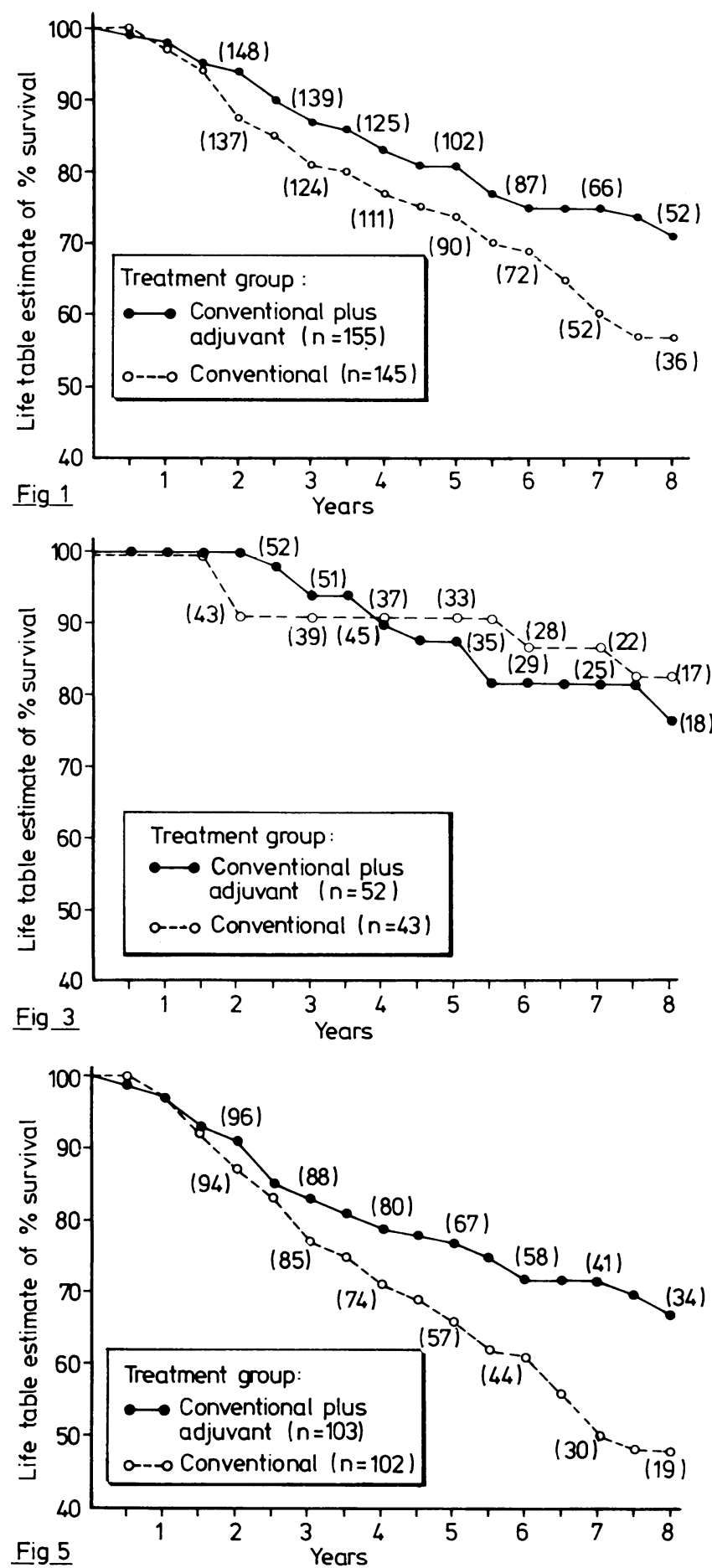
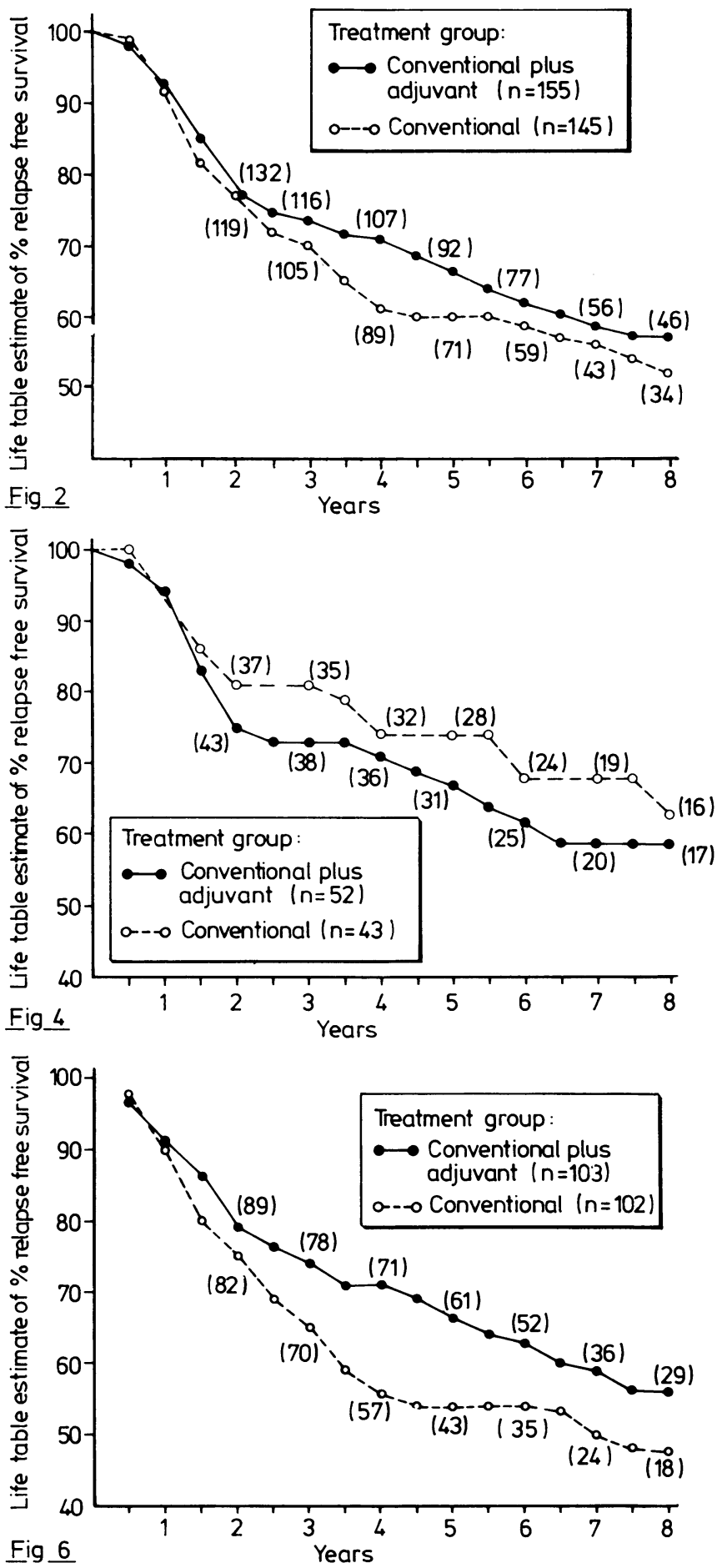

PIG 1-Overall survival curves in the two treatment groups. Numbers of patients followed up given in parentheses. Log rank test: p < $0 \cdot 05$. FIG 2-Relapse free survival curves in the two treatment groups. Log rank test: NS.

FIG 3-Overall survival curves of patients with no evidence of disease in lymph nodes (TNM classification N_). Log rank test: NS.

FIG 4-Relapse free survival curves of patients with no evidence of disease in lymph nodes (N_). Log rank test: NS.

FIG 5-Overall survival curves of patients with evidence of disease in lymph nodes (TNM classification $N_{+}$). Log rank test: $p<0 \cdot 02$.

FIG 6-Relapse free survival curves of patients with evidence of disease in lymph nodes (N.). Log rank test: NS. 


\section{MECHANISM OF ACTION OF ADJUVANT}

Polyadenylic-polyuridylic acid is a non-toxic double stranded complex of synthetic polyribonucleotides and a proved potent modulator of both humoral and cellular immune responses. The complex is also an inducer of interferon. Although results of direct determination of interferon in patients receiving the complex were negative, ${ }^{1}$ in later studies we found an enhancement of interferon mediated protein kinase p67 $\mathrm{K}$ in mouse plasma and $\mathrm{p} 72 \mathrm{~K}$ in human plasma in response to treatment with polyadenylic-polyuridylic acid. ${ }^{5}$ We have also reported that treatment of tumour bearing mice with the complex in association with cyclophosphamide results in a synergistic inhibition of tumour characterised by more retarded tumour growth, lower mortality, and a higher rate of tumour free survival than in mice treated with either agent alone. Furthermore, in these tumour bearing mice receiving such combined treatment there was a significant enhancement of natural killer (NK) cell activity. ${ }^{\circ}$ Recently we have studied in more detail the NK boosting effect of polyadenylic-polyuridylic acid in mice in parallel with an assay of an enzyme marker for the production and action of interferon-namely, 2.5 A synthetase. Enhanced NK cell activity accompanied increased activities of 2.5 A synthetase in mice treated with polyadenylic-polyuridylic acid. ${ }^{7}$ In patients an increase of $\mathrm{NK}$ cell activity as well as an increase of $2.5 \mathrm{~A}$ synthetase activity after one intravenous injection of $60 \mathrm{mg}$ polyadenylic-polyuridylic acid was also observed (A G Hovanessian et al, paper in preparation). In view of these observations we hypothesise that interferon and NK cell activity probably play a part in the overall mechanism of action of polyadenylic-polyuridylic acid as an adjunct to surgery in breast cancer.

Polyadenylic-polyuridylic acid appears to interact with many cell populations, ${ }^{8}$ so that its biological activity might therefore be exerted at different levels. Indeed, in patients 24 hours after a single intravenous injection of $30 \mathrm{mg}$ of the complex we observed that the mean percentage of $\mathrm{E}$ rosette forming cells was significantly $(\mathrm{p}<0.001)$ higher than that found before the injection $(60.8 \% \quad v 51.0 \%)$, confirming our observation on T lymphocytes in mice. ${ }^{9}$

The relevance of the biological effects to the therapeutic action so far observed remains to be determined.

This work was supported by the Cancer Research Institute (New York), CNRS, CNAMTS (Division ASS), and Institut GustaveRoussy.

\section{References}

${ }^{1}$ Lacour J, Lacour F, Spira A, et al. Adjuvant treatment with polyadenylicpolyuridylic acid (polyA-polyU) in operable breast cancer. Lancet $1980 ;$ ii :161-4.

${ }^{2}$ Peto R, Pike MC, Armitage P, et al. Design and analysis of randomised clinical trials requiring prolonged observations of each patient. II. Analysis and examples. Br $\mathcal{F}$ Cancer $1977 ; 35: 1-39$.

3 Bonadonna G, Valagussa P, Rossi A, et al. Multinodal therapy with CMF in resectable breast cancer with positive axillary nodes. The Milan Institute experience. In: Mathe G, Bonadonna G, Salmon S, eds. Adjuvant therapies of cancer. Recent results in cancer research. Berlin: Springer Verlag, 1982:149-56.

Rossi A, Bonadonna G, Valagussa P, et al. Multinodal treatment in operable breast cancer: five-year results of the CMF programme. Br Med f 1981 ;282:1427-31.

${ }^{5}$ Hovanessian AG, Riviere Y, Montagnier L, Michelson M, Lacour J, Lavour F. Enhancement of interferon-mediated protein kinase on mouse and human plasma in response to treatment with polyadenylicpolyuridylic acid (polyA-polyU). F IFN Res 1982;2:209-15.

${ }^{6}$ Youn JK, Lacour $\mathrm{F}$, Hue G. Inhibition of $\mathrm{C} 3 \mathrm{H} / \mathrm{HE}$ mouse mammary tumour growth by combined treatment with cyclophosphamide and polyadenylic-polyuridylic acid. Cancer Res 1982;42:4706-11.

7 Youn JK, Hovanessian AG, Riviere Y, Hue G, Lacour F. Enhancement of natural killer cell activity and 2-5A synthetase in mice treated with polyadenylic-polyuridylic acid. Cell Immunol 1983;79:298-308.

${ }^{8}$ Johnson AG. Modulation of the immune system by synthetic polynucelotides. Springer Semin Immunopathol 1979;2:149-68.

${ }^{9}$ Donner M, Vaillier O, Lacour F. Changes in lymphocyte subpopulations in mice receiving a single injection of polyA-polyU. Ann Immunol Inst Pasteur 1977;128:1039-52.

(Accepted 8 December 1983)

\title{
Beneficial effect of fish oil on blood viscosity in peripheral vascular disease
}

\author{
B E WOODCOCK, E SMITH, W H LAMBERT, W MORRIS JONES, J H GALLOWAY, \\ $M$ GREAVES, F E PRESTON
}

\begin{abstract}
Reports suggest that the low incidence of ischaemic heart disease in Greenlandic Eskimos is related to the effect of a diet rich in eicosapentaenoic acid on platelet reactivity and plasma lipid concentrations. A double blind randomised investigation was therefore conducted of the effects on blood viscosity of dietary supplementation with an oil rich in this fatty acid (1.8 $\mathrm{g} / \mathrm{day}$, given as fish oil) and an eicosapentaenoic acid poor oil (as corn/olive oil)
\end{abstract}

University Department of Haematology and Department of Surgery Royal Hallamshire Hospital, Sheffield

B E WOODCOCK, MRCP, senior registrar

E SMITH, FIMLS, medical laboratory scientific officer

W H LAMBERT, FRCS, senior registrar

W MORRIS JONES, FRCS, consultant surgeon

J H GALLOWAY, BSC, research scientist

$M$ GREAVES, MD, senior lecturer and honorary consultant in haematology

F E PRESTON, MD, reader and consultant in haematology

Correspondence to: Dr F E Preston, University Department of Haematology, Royal Hallamshire Hospital, Sheffield S10 2JF. in patients with peripheral arterial disease. A statistically significant reduction in whole blood viscosity was observed at seven weeks in those patients receiving the eicosapentaenoic acid rich oil. No changes in plasma viscosity, haemoglobin concentration, packed cell volume, or platelet count were seen. A significant fall in plasma triglyceride concentration was also noted only in the patients receiving oil rich in eicosapentaenoic acid; plasma concentrations of cholesterol and high density lipoprotein cholesterol were unchanged.

It is concluded that rheological changes that result from a diet rich in eicosapentaenoic acid may contribute to the suggested protective effects of such a diet against arterial disease and that such changes are of potential therapeutic importance in established arterial disease.

\section{Introduction}

There is now good evidence that Greenlandic Eskimos have a low incidence of myocardial infarction, and there appears to be 